\title{
Comparative Study of Population Aging Trend in Iran and Poland
}

https://doi.org/10.21272/sec5(1).102-116.2021.

Hasan Hekmatnia, ORCID: https://orcid.org/0000-0002-0309-2049

Associate Professor, Department of Geography and Urban Planning, Faculty of Social Sciences, Payam Noor University, Tehran Iran

Kamran Jafarpour Ghalehteimouri, ORCID: https://orcid.org/0000-0003-2699-4456

Research Assistant, Malaysia Japan International Institute of Technology (MJIIT) - Disaster Preparedness \& Prevention Centre (DPPC) \& the Kharazmi University of Tehran, Faculty of Geographical Sciences, Department of Geography and Urban Planning.

Ali Shamsoddini, ORCID: https://orcid.org/0000-0001-9757-4331

Assistant Professor, Department of Human Geography, Faculty of Humanities, Islamic Azad University, Marvdasht Branch, Marvdasht, Iran

\begin{abstract}
Population aging and its consequences are an extremely controversial issue in the global context. An increase in the number of older people along with a decrease in the birth rate leads to an excessive burden on the economically active part of the population. Such imbalances threaten to reduce the workforce, slow economic growth, increase social spending, increase the fiscal burden. Therefore, using the country's own experience to solve the problem of rapid aging of the nation and take measures to improve the quality of life of older people and their social integration into society is insufficient, as changes in the age structure of the population may occur for the first time. Therefore, it is necessary to study and adapt the experience of other countries to address this social issue. The purpose of this study was to conduct a comparative analysis of the aging population in Iran and Poland, as well as to assess the impact of the nation's aging on life expectancy, fertility and gross domestic product (GDP) in these two countries. The object of the study is Poland as a representative of European countries, which is facing an increase in the number of elderly people, and Iran as a country where the age structure of the population is just beginning to change. The study period is 1950-2020. The results of the study show that there has been an increase in the elderly population, but the share of this population compared to other countries is lower. The authors of the study proved the existence of significant differences in the aging population in Poland and Iran. A feature of the demographic situation in Iran is the declining birth rate, which leads to a decrease in the total population and an increase in the proportion of elderly people. These socio-demographic transformations in the long run can have a destructive effect on Iran's GDP. In contrast to Iran, Poland is experiencing an increase in population aging, leading to rising spending on social security and protection, as well as falling GDP. The rapid growth of the elderly population compared to the growth of the total population of the country and the increase in the share of elderly people in the coming years emphasizes the need for further planning of control over the problems associated with this population group.
\end{abstract}

Keywords: population aging, dependency rate, fertility, GDP, Iran, Poland.

JEL Classification: E21, E27.

Cite as: Hasan Hekmatnia, Kamran Jafarpour Ghalehteimouri, Ali Shamsoddini (2021). Comparative Study of Population Aging Trend in Iran and Poland. SocioEconomic Challenges, 5(1), 102-116. https://doi.org/10.21272/sec.5(1).102-116.2021.

Received: 23.12 .2020

Accepted: 09.02.2021

Published: 30.03 .2021 
SocioEconomic Challenges, Volume 5, Issue 1, 2021 ISSN (print) - 2520-6621, ISSN (online) - 2520-6214

Copyright: (C) 2021 by the authors. Licensee Sumy State University, Ukraine. This article is an open access article distributed under the terms and conditions of the Creative Commons Attribution (CC BY) license (https:// creativecommons.org/licenses/by/4.0/).

\section{Introduction}

Aging become a dilemma in most of the developed countries that are known as "population aging". In recent decades, the trends in population aging have increased in European countries, which is a serious challenge for economic growth and income convergence in Europe, and some prospective aging measures which move beyond chronological age and include changes in life expectancy, could better express the experience of recent long-term growth in European economics (Cuaresma et al., 2014).

"According to data from World Population Prospects: the 2019 Revision, by 2050, one in six people in the world will be over age 65 (16\%), up from one in 11 in 2019 (9\%). By 2050, one in four persons living in Europe and Northern America could be aged 65 or over. In 2018, for the first time in history, persons aged 65 or above outnumbered children under five years of age globally. The number of persons aged 80 years or over is projected to triple, from 143 million in 2019 to 426 million in 2050" (UN, 2020).

According to Knodel and Teerawichitchainan (2017), as a country in South Asia, Myanmar has attracted the attention of researchers and policymakers due to its overall poverty levels and relatively rapid population aging. Considering insecurities related to the income of the elderly, the Ministry of Social Welfare had considered the budget as an old-age social pension scheme in two states as pilot projects. In the present century, the issue of population aging and its consequences has become controversial.

Population aging is due to declining birth rates and increased life expectancy, and this concept alone is not relevant to the elderly (Lutz et al., 2008). However, the world is aging rapidly, and geologists and sociologists have a serious task to identify various regions, taking into account the cultural and social subtleties of these territories and applying precise planning for the elderly (Ingersoll-Dayton, 2011). As studies show, planning for population aging requires sufficient knowledge of extensive local differences. In examining the literature on population aging, some issues should be considered, such as: location, area size, financial allocation of councils to population aging, the economic and social contribution of the elderly, and the impact of internal migration on age structure (O'Brien, 2016).

The population's age-structure has contributed to the aging of Australia's population due to declining factors such as fertility and mortality (Ofori-Asenso et al., 2018). Population aging may undermine growth potential and affect countries' economies, as well as slowing the growth of human capital as a whole. In Korea, for example, the fertility rate was 1.23 in 2010, which is much lower than the population growth rate and is expected to decline by 2030. Reducing mortality and rapidly increasing aging is a potential threat to economic growth (Choi \& Shin, 2015). Countries such as Singapore, for example, are identifying the changing needs of an aging population, strengthening the sustainability of existing policies, examining health care and details of the socioeconomic outcomes in the aging process (Malhotra et al., 2019). Furthermore, the speed and scale of aging may vary depending on the challenges of population aging policy in the region. Interventions in national policy (such as raising the pension age) would have different impacts in various parts of a country, such as studies conducted in Russia, and create regional inequalities (Gietel-Basten et al., 2020).

The Active Aging Index (AAI) is designed for $28 \mathrm{EU}$ countries, which is a global tool for a diverse experience of active aging and older people's potential. The Elderly Commission based its political framework for health maintenance and social participation on the definitions of the World Health Organization (WHO) on active aging (Au et al., 2020). On the other hand, the development of public health policies in different countries is important during the aging process in different parts of the world. It is also important to consider the static and aging dynamics of the population in order to address the challenges of aging ( $\mathrm{Li}$ et al., 2019). In the past years, the demographic transition theory was proposed by Thompson (1929), and the world's countries were divided into three categories. The first, group A, where countries are rapidly declining in birth rates, and despite lower death 
rates, the natural increase is reduced, so they are approaching a steady or decreasing population. In the second group, Group B, birth rates are coming under control and the mortality rate is declining faster than the birth rate, consequently, the natural increase rises, or does not decrease to a great extent. In group C, birth rates and deaths are subject to little voluntary control. According to these assumptions, countries will progress from Group $\mathrm{C}$ with high birth and death rates to Group B with a high birth rate and a reduction in the mortality rates, and finally into Group A with a low natality and mortality rates (Véron, 2019).

Global surveys show that there were 703 million elderly people between the ages of 65 and older in 2019. Eastern and South-Eastern Asia (260 million), followed by Europe and North America (over 200 million), respectively, accounted for the largest population in the world. The population of 65 years or older in Iran in 2019 was 5,272, and this number is expected to reach 8,849 by 2030 . In Poland, the number of people aged 65 years and over was 6,846, indicating an older population than in Iran. In Poland, this number is expected to reach 8,579 by 2030, which is lower than in Iran (United Nations, 2019). Statistics show that Iran is on the verge of aging on the Asian continent and may encounter serious socioeconomic problems in the near future (Sabzaian et al., 2019). Demographic changes, including progressive aging, are one of the main challenges to development in Poland, which is one of the reasons for the acceleration of the large-scale migration of the Polish people. This process could have a negative impact on the development potential and quality of life and the economy in the Polish region (Heffner et al., 2019).

In this paper, Poland, as a European country, was compared to Iran in terms of population aging, and the key elements affecting it, such as fertility and life expectancy were analyzed in detail. In the following text, after discussing the theoretical foundations of demographic transition, findings, the world population aging trends, comparison of this trend in the two countries of Iran and Poland, and finally a conclusion and discussion are presented.

\section{Theoretical issues and the literature}

Some assessments have been made on the impact of the demographic transition on economic growth. The changes in age-related imbalance were observed when changing mortality and fertility rates during a demographic transition, taking into account three population variables, which may temporarily boost or slow down. The demographic changes included the growth differential between the population of working-age and the total population, the child dependency ratio, and the old-age dependency ratio. The data showed that GDP per capita growth is positively related to the growth differential between the working-age and the total population, and negatively correlated with child and old-age dependency ratios (Choudhry \& Elhorst, 2010).

The dramatic worldwide demographic transition led to more people living, increased life expectancy, and declining population growth rates. Furthermore, changing demographics related to population aging will have a negative, quantitatively relevant, and long-lasting effect on the natural rate of interest (Carvalho et al., 2017). In general terms, the transition is a shift from a high and uncontrolled level of mortality and fertility to a low and controlled level, and practically all countries have experienced or are currently undergoing the demographic transition. In developed countries such as Mexico, this process of transition is progressing faster than in more developed countries (Partida, 2006).

Changes in demographic rates are seen as indicators of progress in the global transition toward modernization (Zaidi \& Morgan, 2017). However, the modernization trend in contemporary developing populations may be distinct (Hedges et al., 2018). In developed countries, declining population growth is primarily due to low fertility. In contrast, in less developed countries, this declining population is largely due to increased mortality owing to various diseases (Dobriansky et al., 2007). Thus, throughout the second demographic transition, the negative natural population growth is partly balanced by the positive net migration, which results from economic immigration from the less economically developed countries (Kurek, 2011). The process of industrialization, modernization, and urbanization, conspicuously the advancement of medical technology and the improvement of nutritional conditions are the main factors of demographic transition, which reduces mortality and birth rates due to improving education level and innovation of contraceptive methods. In China, demographic transition has provided a window of opportunity for economic growth and the potential for socioeconomic development (Yuan 
\& Gao, 2020). The process of modernization in economically-advanced countries such as Italy is intended to shift to new types of social, economic, and political systems which are closely linked to demographic transition (Salvati et al., 2019).

The role of mortality has long been substantial in the concept of demographic transition, which has been a major factor in triggering fertility decline in the late nineteenth century at a societal and a familial level. To elaborate, reducing childhood mortality is an apparent reason for the steady decline in marital fertility. The conceptual changes to increase investment in human capital of children and increasing opportunity costs for women as they are integrated into market work outside the family will reduce the demand for children. In general, social and cultural developments and technological innovation are in the process of modernization and may have influenced childhood survival and the choice of reproductive choice (Reher et al. 2017). In addition, bidirectional feedbacks between the education component of the population, technological progress, and demographic change (in particular mortality) ultimately led to economic growth (Cervellati \& Sunde, 2015).

The onset of the modernization process, including the reorganization of politics, the economy, and social life, was due to numerous factors. The impact of modernization on incomes was strongly dependent on the timing of the phases of the demographic transition in various regions (Korotayev et al., 2015). The investigation shows that there has been evidence that time has affected the growth of countries since the onset of the demographic transition and this conjecture is based on the insights of the unified growth literature that models the take-off from stagnation to sustainable growth as the result of a massive, non-recurring demographic transition that indicates declining infertility and increasing widespread education (Cervellati et al., 2019).

In demographic terms, population aging is explained by the demographic transition process, which affects all populations in the world and is complete in countries such as France or the United States. This transition is in line with the shift from a population regime with a high birth rate and mortality to a regime characterized by a low birth and death rate, with low population growth at both stages (Macia et al., 2019). In this paper, based on demographic transition theory and comparative evaluation, the population aging process between Iran and Poland is presented.

\section{Method}

The present study is a kind of applied-developmental research that has been done using the descriptive-analytical method. This method is very suitable for non-quantified topics and issues. The main part of statistics and information were collected using a library-documentary method. However, this method can match with the other quantitative models. It should be noted that various indicators of aging (average and middle age over 65 years), indicators of total fertility, and life expectancy for Iran and Poland were derived from the United Nations Population Division (2020) data. Also, the aging index was met by the ratio of people aged 65 and over to the total population (Shryock \& Siegel, 1971). In this study, the aging index showed the rate of increase in the elderly population per population of 0-14 years and the ratio of the number of elderly people aged 65 and over to the population under the age of 15 was multiplied by 100 (Safarkhanlu \& Rezaei Ghahroudy, 2017).

\section{Finding and discussion}

\subsection{The world population aging trends}

According to the World Population Outlook (2020), prepared by the United Nations Department of Economic and Social Affairs, the share of the world's population aged 65 and over ranged from 5.8 percent $(128,709$ million) in 1950 to 9.3 percent $(727,606$ million of people) by 2020 and is projected to increase to $15.9 \%$ (1548,852 million) by 2050 (UNDPSA, 2020). Although there is an increase in the share of the elderly population in all parts of the world, inter-continental comparisons show that there is a significant variation between different parts of the world. The share of the population over the age of 65 in Europe in 2020 was 19.1\%, which is the highest level compared to Asia (8.9\%) and Africa (3.5\%). North American regional countries are 16.8 percent older than European countries. This could be due to the fact that European and North American countries have experienced much lower mortality, higher life expectancy, and fertility transmission than Asian and African countries. Oceania, with 
12.8 percent, and Latin America, with 9 percent, possess lower populations over the age of 65 than in Europe (Fig. 1).

A comparison of different regions of Europe shows that Southern Europe, with a population of 21.4 percent over the age of 65, is at the highest level compared to other parts of Europe. Western Europe with 20.8 percent, Northern Europe with 19 percent, and Eastern Europe with 16.8 percent are in the next ranks in terms of the population over 65 years (Fig. 1). European countries, along with economic growth and increasing women's employment, have experienced declining birth rates and even negative growth rates in many countries. The rapid rise in the share of the elderly in Europe could put enormous pressure on various economic sectors in Europe, such as the pension and health systems, and would ultimately hinder the economic growth of those countries.

From the total of 40 European countries, 37 have entered aging before 2010 (the percentage of the population over 65 was more than $10 \%$ ), only 3 European countries did not enter this stage of demographic transition until 2010, one of these countries are in the Western European region and the other two nations are in the Southern European region. Of course, the percentage of people over the age of 65 in all three countries is about 10 percent. Therefore, it might be rational to opine that the population of these countries is on the verge of aging (Darabi \& Torabi, 2017). Poland, an Eastern European country, has been aging since 1990. The country's share of the population over the age of 65 was 5.2 percent in 1950, rising to 10 percent in 1990, and eventually reached 18.7 percent in 2020 (Fig. 1).

As shown in Figure 1, the situation of countries in Asia is different in terms of aging. Many Asian countries have not yet entered old age. A comparison of different parts of Asia shows that East Asia, with 13.6 percent of the population over the age of 65, is at the highest level compared to different parts of Asia and is entering old age. Also, 7.9 percent of Central and South Asia, 7.2 percent of Southeast Asia, 6.2 percent of South Asia, and 5.9 percent of West Asia are over 65 years old. In Iran, the share of the population over the age of 65 has risen from 5.3 percent in 1950 to 6.6 percent in 2020 . These changes indicate that although Iran's elderly population has increased significantly during the period under study (1950-2020), the share of this demographic group is still lower than in developed and developing countries (Fig. 1).

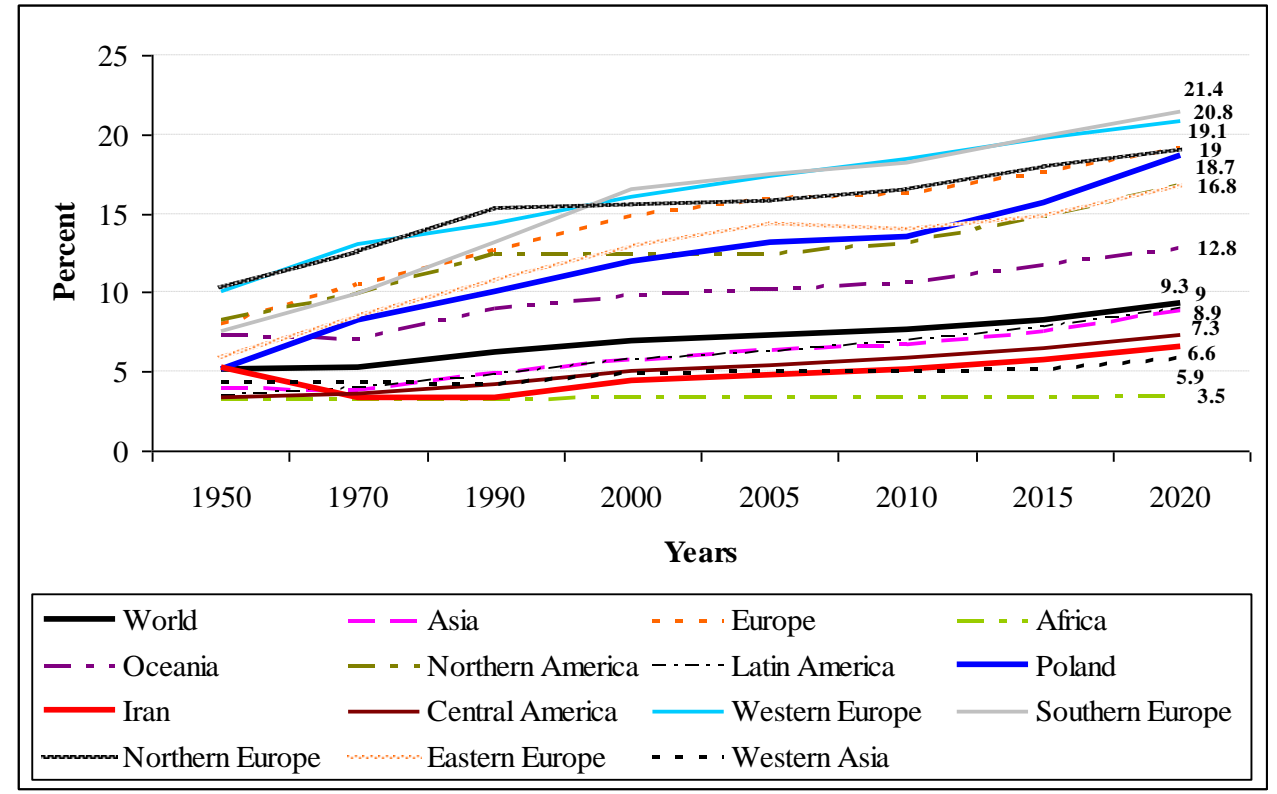

Figure 1. The share of the population aged 65 and over in different continents of the world and in Poland and Iran during the years 1950 - 2019

Source: United Nations, 2019.

\subsection{Varied age groups share comparison in total population}


A Comparison of the population share of varied age groups in Figure 2 is presented for different continents, Iran and Poland in 2020. The results show that the population is relatively young in many parts of the world, considering children under the age of 15 making up 40.3\% of the population in Africa. Europe, North America, Latin America, and Asia have experienced more fertility reduction, with a lower percentage of children $(16.16 \%$, $18.1 \%, 23.9 \%$, and $23.5 \%$, respectively). Poland, with 15.2 percent of children under the age of 15 , is lower than the global average and other surveyed areas (Fig. 2), with the exception of Southern Europe. Poland also has experienced the lowest share of the 15-64 age group, at 66.1 percent (24,995 million), with an active and workingage population, compared to Eastern Europe, and the highest rate compared to other parts of Europe.

Among the regions surveyed in Figure 2, Iran, with a population of $24.7 \%$ under the age of 15, was ranked after West Asia, Central America, and the world average. In other words, Iran has a relatively young population compared to other surveyed areas and is in middle age and on the verge of aging. Iran's regional comparison shows that Iran is younger than East Asia (17.1\%), which can be attributed to population control (fertility) in China, Japan, and South Korea in recent decades. Moreover, with the progress made in these countries and the entry of women into different job sectors, it has also had a negative impact on the fertility rate. In West Asia, the population share under 15 years was 28.1 percent and considering Iran's location in the region, it is estimated that Iran is about 3.4 percent older than West Asian countries (Figure 2). 68.7\% of Iran's population (57.7 million people) are in the 15-64 age group. Given that the active population and working-age were in this population group, it can be argued that Iran has favorable conditions in terms of active population status (Fig. 2).

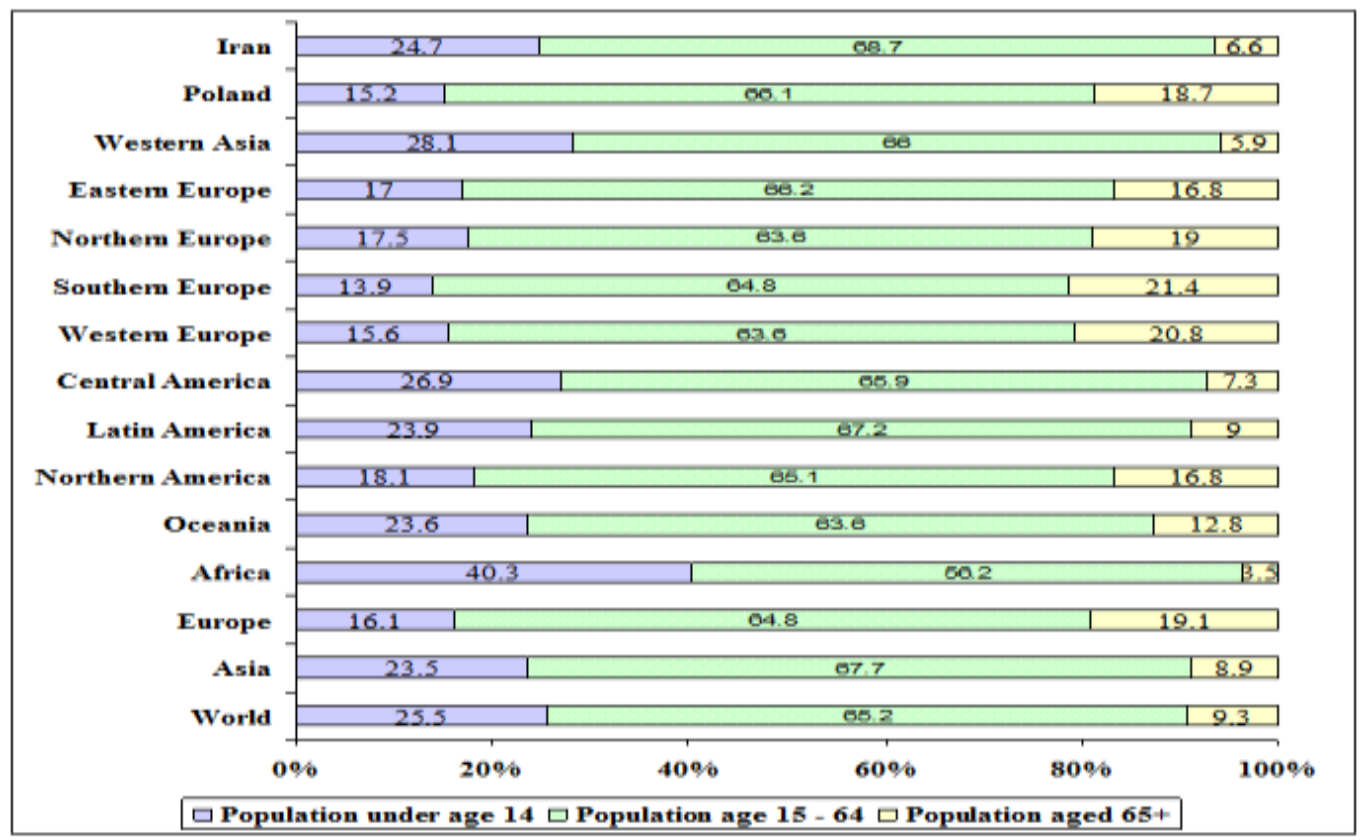

Figure 2. Collective share of various age groups in different continents of the world, Poland and Iran in 2020

Source: United Nations, 2019.

\section{Comparison of age pyramids in Iran and Poland}

The age pyramids of Iran and Poland (Figure 3) show that Iran is in the population middle age and they will gradually get into the aging population from the threshold of aging unless proper socio-economic and appropriate measures are taken by the authorities. As illustrated in Figure 3, the rule of the age pyramid of Poland is smaller than the rule of the age pyramid of Iran. It should be noted that in this part of the age pyramid, there are groups under 15 years old. The possible reasons for this situation in the Polish age pyramid rule section are the early decline in fertility in Poland, population control policies, and demographic transition. However, in Iran, issues such as changing lifestyles, industrialization, and consequently the widespread entry of women into employment following the change in the social order from agriculture to industry and services, especially after the Islamic 
Revolution in Iran (1979), with the start of Iraq's imposed war on Iran and its prolongation, population growth policies were pursued in the 1980s, and the country's birth rate rose sharply to 3.91 percent. In the 1980s, the birth rate in Iran was so high that the average age of the population in the mid-1980s reached 21.7 years, indicating the youth population in Iran. However, in the 1990s and 2000s, due to the age of activity and employment, these people needed various facilities, including educational, welfare, and health facilities, and as a result, some limitations, problems, and shortcomings were created. All these shortcomings, as well as the special economic situation in Iran in the 1990s, led to the implementation of population reduction policies in the country, which has reduced the rapid growth of population in Iran (Fig. 3).

In general, based on the results of Figure 3, it can be said that Iran's age pyramid is younger than Poland, however, industrialization in Poland started earlier than Iran and has seriously damaged the population structure. With all these interpretations, if these countries do not make a policy in the new social and political program, they will have a severe aging problem in the future (Fig. 3).

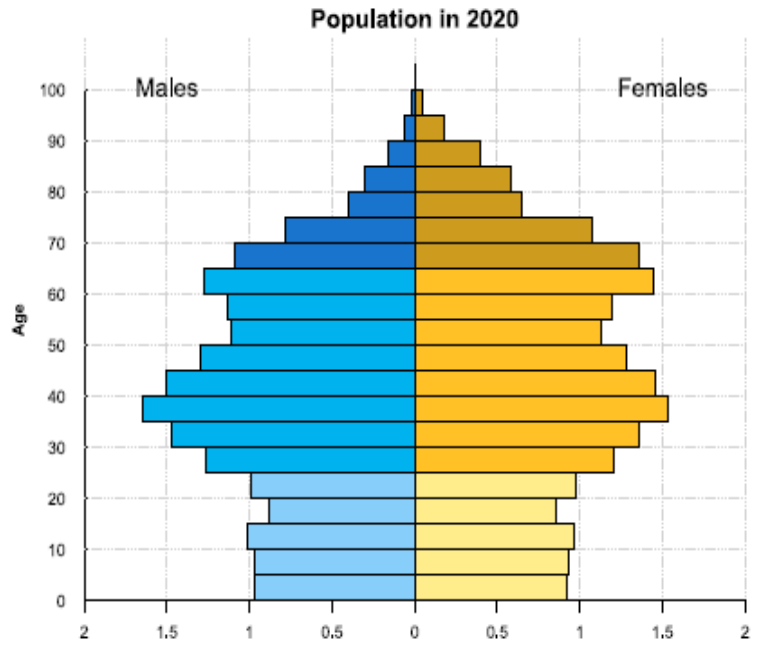

Poland

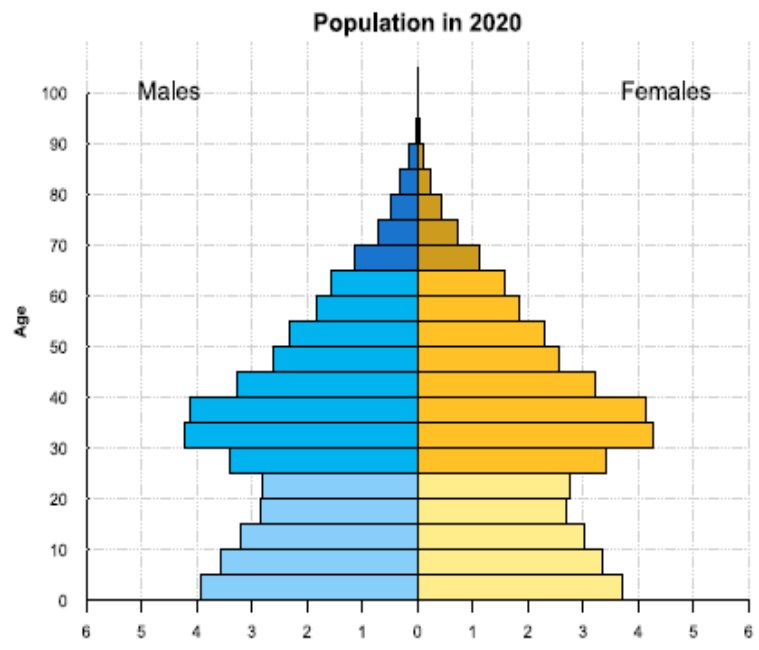

Iran

Figure 3. Age and gender structure of Poland and Iran, 2020

Source: United Nations, 2019.

\subsection{Comparing the aging process of Iran and Poland}

Table 1 shows the status of the elderly population in Iran and Poland. As shown, the elderly population in Iran increased from 903,000 in 1950 to 5.5 million in 2020, and in other words, in Iran, during the seventy years of study, 4.6 million people have added to the elderly population. . Also, shows, the elderly population of Poland in the years under review (1950-2020) has increased from 1,298 million to 7,092 million. For further explanation, between 1950 and 1920, 5,792 million people were added to the country's elderly population.

Based on the results obtained from Table 1, it was observed that the trend of the median age index from 1950 to 2020 in Iran and Poland has an upward trend, so that the average age in Iran during 1950, from 21.9 to 32 in 2020. The index has also risen to 25.8 in Poland since 1950 and 41.7 in 2020 (Table 1). In general, in demographic studies, when the median age of the population is less than 20 years old, the population is young, if the median age is between 20 and 30 years old, the population is middle-aged, and the population with more than 30 years old is in aging. According to this population index, Iran is at the beginning of demographic aging, and the Polish population has entered the population aging since 1990. Comparison of the two countries shows a difference of 9.7 years in the median age index, so, based on this index, it can be said that Iran's population is much younger than Poland. The results of Table (2) are related to the study of the status of aging indicators during different statistical periods from 1950 to 2020 in Iran and Poland. Also, Figure 4 shows the population growth trend. Comparing the population growth rate of Iran and Poland shows that the population growth trend in Iran in 1950 
was 2.4 percent per year, which in 1990 rose to 3.5 percent per year, but with the implementation of population control policies in Iran after the eight-year imposed war (1980), this trend has decreased, so that in 2020 it has decreased to 1.4 percentage. In Poland, the growth rate of the population decreased from 1.9 percent in 1950 to 0.4 percent in 1990, and this trend continued to decrease in the population rate until 2005 so that the growth rate of the Polish population in 2005 reached -0.1 per year. It should be noted that the country's population growth trend in 2010 increased almost to zero, but in 2020 it re-entered the downward trend and returned to the situation in $2005(-0.1)$.

Table 1. Population Indicators and Projections for Poland and Iran

\begin{tabular}{|c|c|c|c|c|c|c|c|c|}
\hline & \multicolumn{2}{|c|}{ Median age (in years) } & \multicolumn{2}{|c|}{$\begin{array}{c}\text { Percentage of population } \\
\text { aged } 65+\end{array}$} & \multicolumn{2}{|c|}{$\begin{array}{c}\text { Elderly Index age } 65 \text { and } \\
\text { over /under age } 15\end{array}$} & \multicolumn{2}{|c|}{$\begin{array}{c}\text { Total dependency } \\
\text { ratio }\end{array}$} \\
\hline & Iran & Poland & Iran & Poland & Iran & Poland & Iran & Poland \\
\hline 1950 & 21.9 & 25.8 & 5.3 & 5.2 & 14.5 & 17.7 & 155.9 & 116.8 \\
\hline 1970 & 17.7 & 28.1 & 3.4 & 8.2 & 7.5 & 30.1 & 192.1 & 120.3 \\
\hline 1990 & 17.2 & 32.2 & 3.3 & 10 & 7.2 & 39.6 & 207.8 & 96.6 \\
\hline 2000 & 21.2 & 35 & 4.4 & 12 & 12.9 & 61.4 & 168.1 & 94.2 \\
\hline 2005 & 24.1 & 36.6 & 4.8 & 13.1 & 17.7 & 78.7 & 132.2 & 85 \\
\hline 2010 & 27 & 38.1 & 5.1 & 13.5 & 21.4 & 88.5 & 102.8 & 74.6 \\
\hline 2015 & 29.7 & 39.7 & 5.8 & 15.7 & 24.3 & 105.9 & 83.8 & 73.5 \\
\hline 2020 & 32 & 41.7 & 6.6 & 18.7 & 26.5 & 123.1 & 80.2 & 77.7 \\
\hline
\end{tabular}

Source: United Nations, 2019.

According to the demographic transition theory, Poland is a country that has started the process of reducing fertility and increasing life expectancy much earlier than Iran. The total fertility rate in Iran was almost twice the total fertility rate in Poland in 1950, while in 2020 it has a declining trend and decreased 1.5 times. As shown in Table (2), the trend of increasing life expectancy in both countries has always been steadily on the rise from 1950 to 2020. Although the difference in life expectancy between the two countries at the beginning of the period (1950) was about 20.8 years (61.4 years in Poland versus 40.6 years in Iran), this difference in life expectancy has been steadily declining over the course of the study period. Thus, this difference in 2020 has reached 2.1 years. The difference between life expectancy and total fertility rate, in the years under review, is the most important factor in the difference in aging between Iran and Pakistan.

Table 2. Population Indicators and Projections for Poland and Iran

\begin{tabular}{|c|c|c|c|c|c|c|c|c|}
\hline & \multicolumn{2}{|c|}{ Population (in millions) } & \multicolumn{2}{|c|}{ Growth rate $(\%)$} & \multicolumn{2}{|c|}{ Fertility rate } & \multicolumn{2}{|c|}{$\begin{array}{l}\text { Life expectancy } \\
\quad \text { (in years) }\end{array}$} \\
\hline & Iran & Poland & Iran & Poland & Iran & Poland & Iran & Poland \\
\hline 1950 & 17.1 & 24.8 & 2.4 & 1.9 & 6.91 & 3.63 & 40.6 & 61.4 \\
\hline 1970 & 28.5 & 32.6 & 2.7 & 0.8 & 6.68 & 2.33 & 49.2 & 69.8 \\
\hline 1990 & 56.3 & 37.9 & 3.5 & 0.4 & 5.62 & 2.16 & 60 & 70.7 \\
\hline 2000 & 65.6 & 38.5 & 1.3 & 0.1 & 2.4 & 1.51 & 69.1 & 72.7 \\
\hline 2005 & 69.7 & 38.3 & 1.2 & -0.1 & 1.92 & 1.26 & 71.2 & 74.6 \\
\hline 2010 & 73.7 & 38.3 & 1.1 & 0 & 1.82 & 1.37 & 72.7 & 75.6 \\
\hline 2015 & 78.4 & 38 & 1.2 & -0.2 & 1.91 & 1.33 & 75 & 77.2 \\
\hline 2020 & 83.9 & 37.8 & 1.4 & -0.1 & 2.15 & 1.42 & 776.4 & 78.5 \\
\hline
\end{tabular}

Source: United Nations, 2019. 


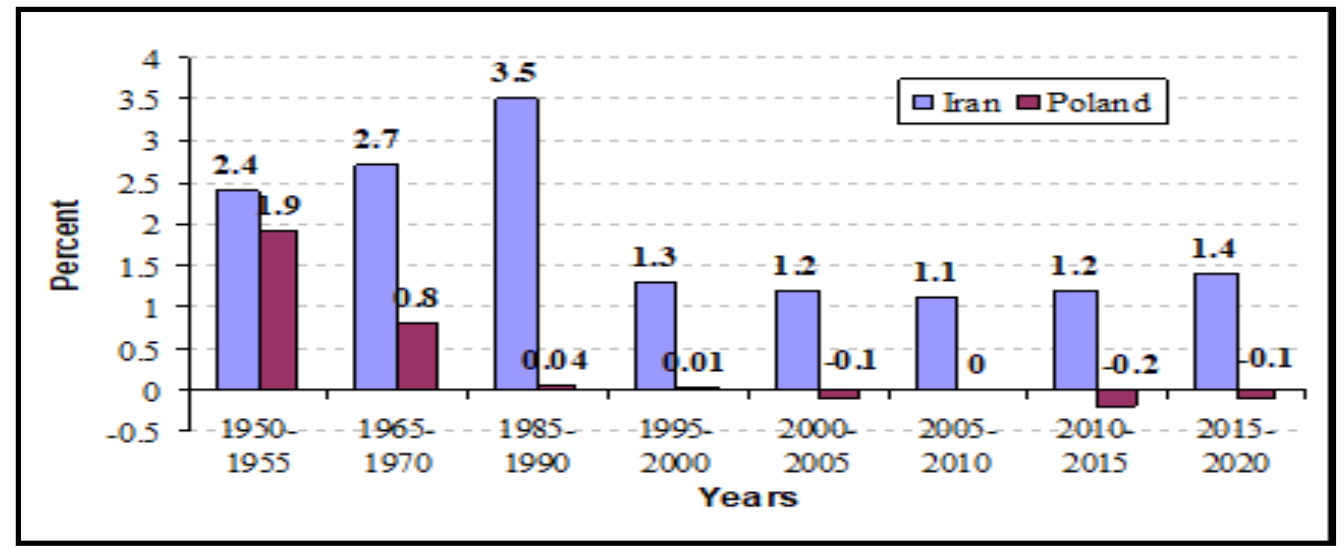

Figure 4. Annual population change rate (percent) for Poland and Iran

Source: United Nations, 2019.

One of the population indicators that show changes in the size of the elderly population is the aging index. This index shows the rate of increase in the elderly population per population of 0-14 years and the ratio of the number of elderly people aged 65 and over to the population under the age of 15 multiplying by 100 (Safarkhanlu \& Rezaei Ghahroudy, 2017). Figure 5 shows the trend of the population aging index in Iran and Poland. As can be seen, the population aging index in the 1950s was 14.5 in Iran and 17.7 in Poland. This difference has increased since the 1970s, with the Polish aging index reaching a further four times that of Iran. Therefore, it can be said that the aging process in Poland started much earlier than in Iran so that in 2020, it has reached 4.7 times. The results of Figure 5 show that the aging index in Iran in the 1990s had a declining trend, reaching 7.2 in 1990. It has been on the rise since the 1990s, reaching 26.5 in 2020 .

Given the evolution of the population aging in Iran and Poland, effective planning is needed to meet the needs of older people, whose population will grow more rapidly in the coming decades. On the one hand, this process has led to the aging of the labor, service, or security forces. On the other hand, in addition to the shortage of alternative youth, additional forces are needed for elderly care. As aging progresses, the number of patients and disabled people in the elderly will exceed that of other groups, which needs to be considered in planning for health care. Admittedly, due to the special limitations of the elderly in order to meet their basic needs, it is substantial to implement educational programs and culture in the community and household in the field of aging and the elderly.

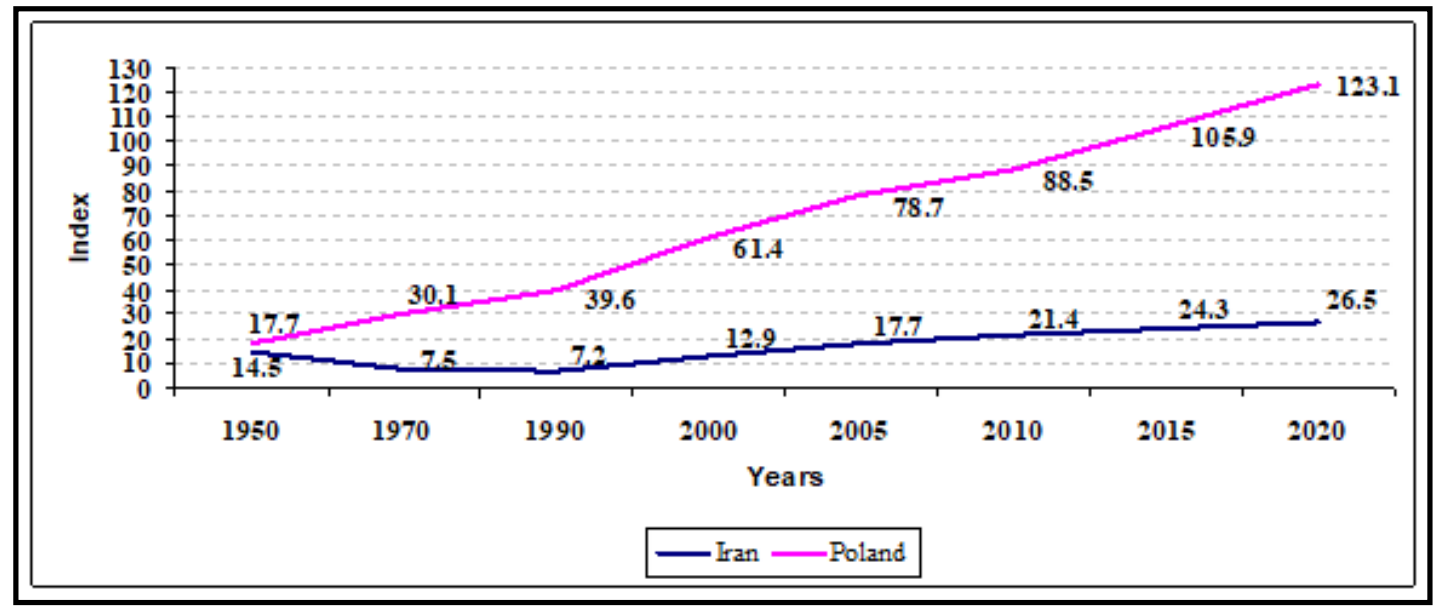

Figure 5. Elderly Index for Poland and Iran

Source: United Nations, 2019.

\subsection{Comparison of fertility between Iran and Poland}


One of the effective indicators in increasing aging has been total fertility, which is noticeable in the results of comparing this index for both Iran and Poland in Figure 6. As shown in Figure 6, the value of this index in Iran for 1950 was 6.91, after this period until 1990, it had an almost constant trend, and in 1990 onwards, this index has decreased, so that in 2015 it has reached the minimum possible (1.82). From 2015 onwards, factors such as propaganda policies, religious views, and the late maturation of the 1980s marriage have led to a slight increase in the total fertility to 2.15. In Poland, the fertility index in 1950 was 3.63, which was almost declining until 2005 and has gone through a relatively stable trend from this decade (Fig. 6).

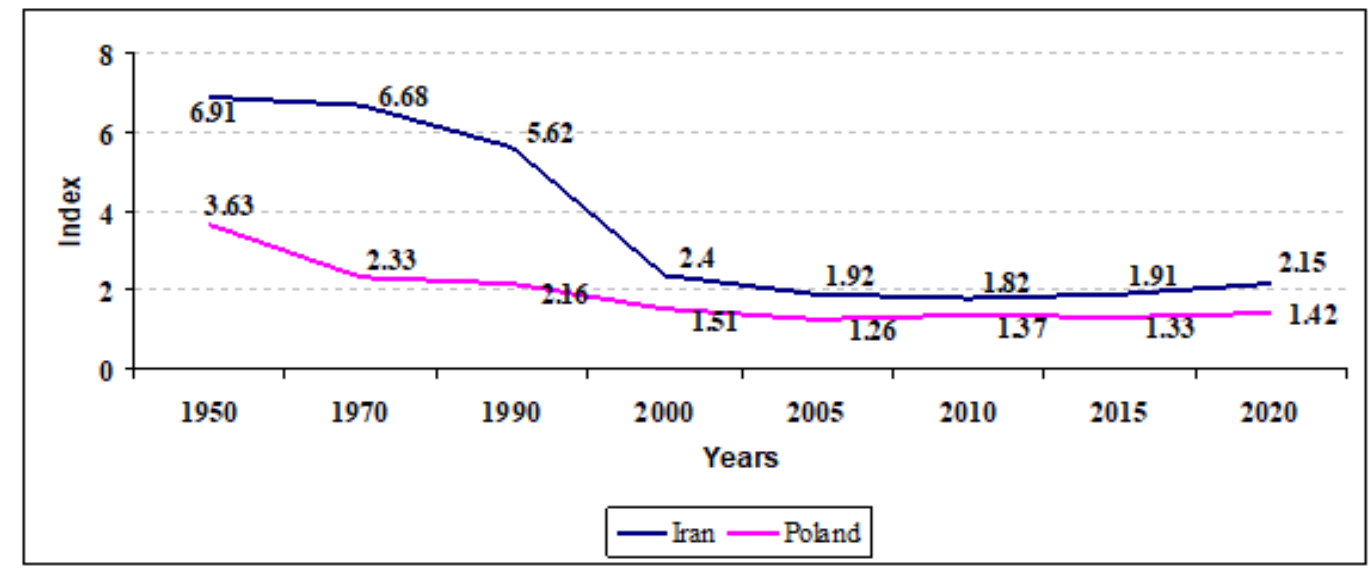

Figure 6. Fertility rate for Poland and Iran

Source: United Nations, 2019.

\subsection{The effect of aging on the dependency rate in Iran and Poland}

The results of Figure 7 provide an overview of total dependency rates from the 1950s to 2020 in Iran and Poland. As can be observed, the trend of this index in Poland has been upward until the 1970s and then has been declining since the 1990s. Since 2015, the overall dependency rate in Poland has been on a very slow upward trend. However, as can be seen in Figure 7, the status of the total dependency rate trend in the population of Iran is different from Poland. The trend of the index until the 1990s was upward in Iran and then entered a downward trend. In general, it can be illustrated that due to the younger population in Iran and the different retirement ages in the two countries, this difference is in the index in both countries.

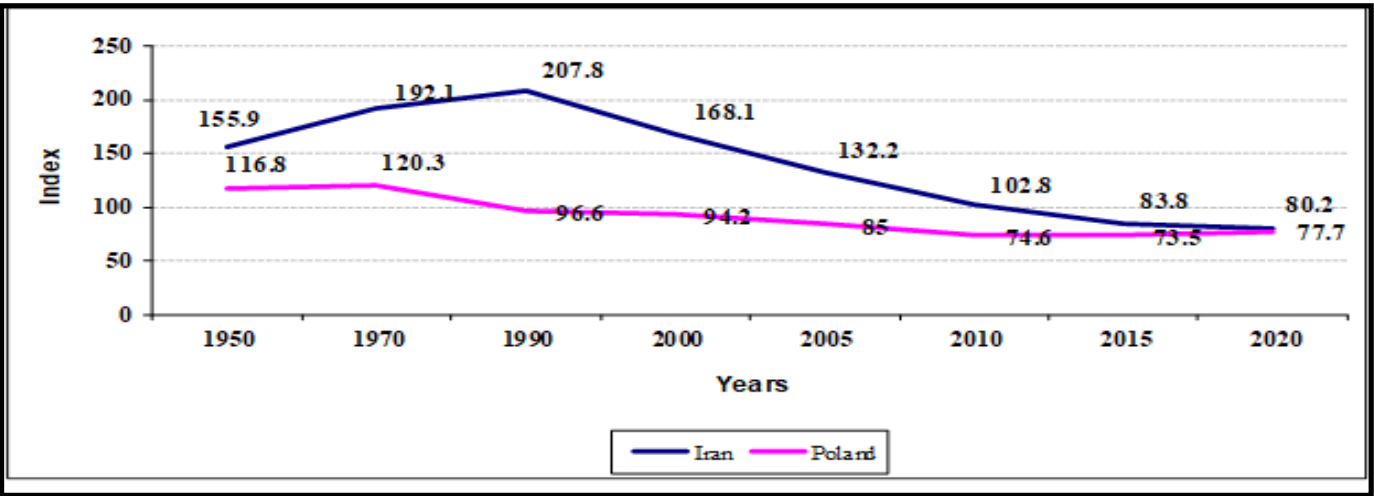

Figure 7. Total dependency ratio for Poland and Iran

Source: United Nations, 2019.

\subsection{The effect of aging on Gross Domestic Product (GDP)}


From 1961 to the end of 1976, Iran's GDP rose from 52,000 billion rials to 242,000 billion rials (at constant 1997 prices). In fact, Iran's economy has grown 4.7 times over the past 15 years. Beginning in 1977, the production process reversed and began to decline. The declining conditions of production continue due to the instability of the revolution, and then the start of the Iran-Iraq war, so that production by $30 \%$ reduction, from 242 thousand billion rials in 1976 reached 170 thousand billion rials at the end of 1981. After that, despite the increase in production in 1981 and 1982, the downward trend continued until 1988 (the end of the war). On the contrary, since 1989, the upward trend in production has resumed, and except for a three-year period (from 1993 to 1996) when production increases stopped, the upward trend continued in production until the end of 2011. So that production from 180 thousand billion rials in 1988, reached 570 thousand billion rials in 2011 and finally, despite economic embargoes in the last 5 years, has increased to 1676 thousand billion rials in 2018. In fact, Iran's economy has grown 9.3 times over the 57 years since the war. It can be claimed that the trend of GDP in Iran has had fluctuated and has always been affected by factors such as war, regional insecurity, financial debts, oil price instability, and severe economic embargoes. In contrast, GDP in Poland has always been on the rise, indicating that the country's economic situation has been less affected by regional political and economic developments.

One of the components that must be considered in relation to GDP in Iran and Poland is the aging population. According to the United Nations Population Fund, although Iran's population currently has a middle-aged population, the population will be aged in the coming years, according to the population pyramid. According to Figure 8, Iran's GDP grew exponentially until 1990. In this year, 3.3\% of the total population of Iran, which means 1855,000 people, were over $65 \%$, and $64.3 \%$ (that is 28835,000 people) were active and influential in increasing GDP, and this trend will continue until 2018. And the ups and downs have continued. The important issue here is the productivity of labor and production in Iran over the age of 65, so that the level of activity and work among this population up to the age of 75, while the labor force in Poland shortly after reaching its peak, it plummets rapidly to zero. Therefore, the continuation of the aging process in Poland, if an economic crisis occurs in this country, will overshadow the country's gross domestic product.

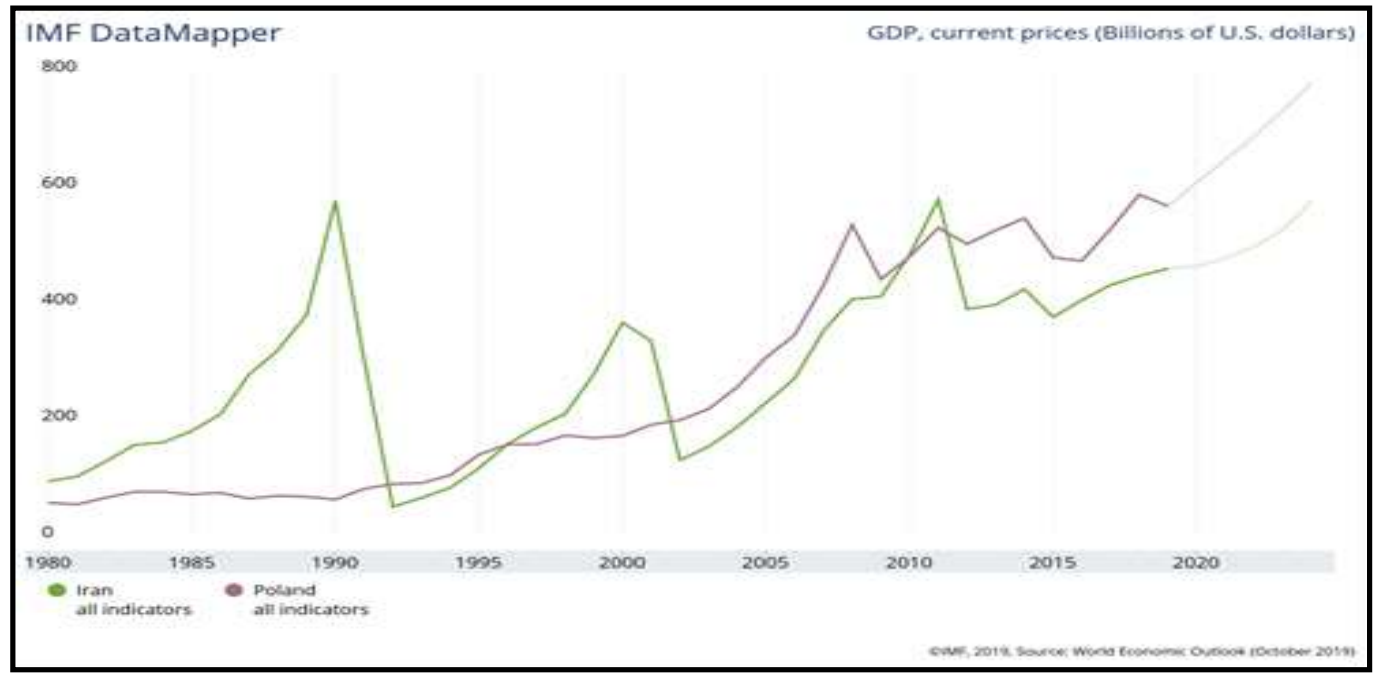

Figure 8. GDP of Poland and Iran

Source: United Nations, 2019.

\section{Conclusion}

Based on the results of this study, it was obtained that in the two target countries, Poland and Iran, the median age index in the studied periods (1920-2020) had an upward trend. The average age of natural populations usually fluctuates between 15 and 40 years. It is worth mentioning that when the age composition of a country is close to 15 , the population is young, and when this age composition is close to 40, the elderly population is considered (Kazemipour, 2009; Mahmoudi, 2016). On the other hand, Sheriac and Siegel (1971) state that if the population has an average age of 20 to 30 years, it would be a middle-aged population, and a population with an average age 
of 30 years and older will be considered elderly. (Shryock \& Siegel, 1971). Taking into account the aforementioned points, it can be realized that the population of Iran was at the beginning of the aging phase, while the population of Poland was in the aging phase and it has been about two decades since this country entered the aging period. Other indicators were total fertility and life expectancy. The results showed that in the two countries studied, the fertility rate had a decreasing trend and the life expectancy level had an increasing trend compared to the 1950s. Age structure transition is a complementary part of the demographic transition process. Fertility and mortality declines that occur in the context of demographic transition lead to fundamental changes in the age structure of the population. Increasing life expectancy at birth in the early stages of demographic transition increases the population of children, and in the final stages of transition, its raise leads to an increase in the elderly population (Ezzati et al., 2009). Of course, changes in mortality are less likely to affect the age distribution than fertility changes, on account of that mortality reduction usually affects all ages, while fertility declines will be affected the number of newcomers to the population in the age pyramid. Thus, short lives, high birth rates, slow population growth, and the young population structure will exist before the onset of demographic transition. In a demographic transition, at first mortality and then fertility decreases; and as a result, population growth initially increases rapidly, then decreases again. Eventually, moving toward lower fertility and increased life expectancy, population aging will be formed.

Moreover, with the increase in the life expectancy index, the population aging in Iran, Poland, and other countries in the world is increasing, which will be considered a particularly noteworthy and influential factor in the socioeconomic system of each country. Aging will have its own special issues such as increased disability and weakness in old age, multiple illnesses simultaneously, chronic and incurable illness, exposure to multiple medications together, and susceptibility to certain diseases. (Faraji Sabkbar et al., 1397). Admittedly, as the population gets older, the double burden of disease and the increased risk of disability lead to the development of chronic diseases, resulting in increased costs and a decline in the quality of life (Kalantari, 1996). It would be rational to draw this subject that in Iran, the probability of a fundamental and continuing reduction in mortality dates back to the years immediately after World War II. Over the years, vaccinations have become widespread and attention has been paid to the health of children in schools, and more and more measures are being taken in these cases, and in these years, organized efforts have been made to eradicate and treat some diseases, especially malaria and tuberculosis (Mirzaei, 2005).

To sum up, the present study showed that although the population aging in Iran during the study period (19502020) has increased, but still the share of this population group compared to other countries in the world, including developed and developing countries, is at a lower level. In general, in the current situation, there is a big difference between the rate of aging in Poland and Iran. In Iran, which is on the verge of aging, declining population growth is not the main concern, but the change in the total fertility is important, which will reduce the country's population and thus reduce fertility and increase the number of elderly people and in the long run, it will negatively affect Iran's GDP. In contrast, in Poland, an economic crisis will lead to a reduction in the share of manpower participation (population aging) in job development, a reduction in the burden of higher welfare costs on the workforce, and ultimately a sharp decline in GDP.

Funding: self-funded.

Author contribution: conceptualization, Hasan Hekmatnia, Kamran Jafarpour Ghalehteimouri, Ali Shamsoddini; data curation, Hasan Hekmatnia, Kamran Jafarpour Ghalehteimouri, Ali Shamsoddini; formal analysis, Hasan Hekmatnia, Kamran Jafarpour Ghalehteimouri, Ali Shamsoddini; funding acquisition, Hasan Hekmatnia, Kamran Jafarpour Ghalehteimouri, Ali Shamsoddini; investigation, Hasan Hekmatnia, Kamran Jafarpour Ghalehteimouri, Ali Shamsoddini; methodology, Hasan Hekmatnia, Kamran Jafarpour Ghalehteimouri, Ali Shamsoddini; project administration, Hasan Hekmatnia, Kamran Jafarpour Ghalehteimouri, Ali Shamsoddini; resources, Hasan Hekmatnia, Kamran Jafarpour Ghalehteimouri, Ali Shamsoddini; software, Hasan Hekmatnia, Kamran Jafarpour Ghalehteimouri, Ali Shamsoddini; supervision, Hasan Hekmatnia, Kamran Jafarpour Ghalehteimouri, Ali Shamsoddini; validation, Hasan Hekmatnia, Kamran Jafarpour Ghalehteimouri, Ali Shamsoddini; visualization, Hasan Hekmatnia, Kamran Jafarpour Ghalehteimouri, Ali Shamsoddini; writing - 
original draft, Hasan Hekmatnia, Kamran Jafarpour Ghalehteimouri, Ali Shamsoddini; writing - review \& editing, Hasan Hekmatnia, Kamran Jafarpour Ghalehteimouri, Ali Shamsoddini.

\section{References}

1. $\mathrm{Au}$, Doreen W.H., Jean Woo, and Asghar Zaidi (2020). Extending the active ageing index to Hong Kong using a mixed-method approach: Feasibility and initial results. Journal of Population Ageing, 1-16, Available at: https://www.researchgate.net/scientific-contributions/Doreen-W-H-Au-2001524986.

2. Carvalho C., Ferrero A., Nechio F. (2017). Demographic transition and low us interest rates. FRBSF Economic Letter, Federal Reserve Bank of San Francisco. Available at: https://ideas.repec.org/a/fip/fedfel/00142.html.

3. Cervellati, Matteo, and Uwe Sunde (2015). The economic and demographic transition, mortality, and comparative development. American Economic Journal: Macroeconomics, 7(3), 189-225. Available at: https://pubs.aeaweb.org/doi/pdfplus/10.1257/mac.20130170.

4. Cervellati, Matteo, Gerrit Meyerheim, and Uwe Sunde (2019). The timing of the demographic transition and economic growth. Economics Letters, 181, 43-46. Available at: https://ideas.repec.org/a/eee/ecolet/v181y2019icp43-46.html.

5. Choi, Ki-Hong, and Sungwhee Shin (2015). Population aging, economic growth, and the social transmission of human capital: An analysis with an overlapping generations model. Economic Modelling, 50, 138-147. Available at: https://ideas.repec.org/a/eee/ecmode/v50y2015icp138-147.html.

6. Choudhry, Misbah T., and J. Paul Elhorst (2010). Demographic transition and economic growth in China, India and Pakistan. Economic Systems, 34(3), 218-236. Available at: https://ideas.repec.org/a/eee/ecosys/v34y2010i3p218-236.html.

7. Cuaresma, Jesus Crespo, Martin Lábaj, and Patrik Pružinský (2014). Prospective ageing and economic growth in Europe. The Journal of the Economics of Ageing, 3, 50-57. Available at: https://ideas.repec.org/a/eee/joecag/v3y2014icp50-57.html.

8. Dobriansky, Paula J., Richard M. Suzman, and Richard J. Hodes (2007). Why population aging matters: A global perspective. National Institute on Aging, National Institutes of Health, US Department of Health and Human Services, US Department of State. Available at: https://www.free-ebooks.net/medicalacademic/Why-Population-Aging-Matters-A-Global-Perspective/pdf?dl\&preview.

9. Ezzati M., Mozaffari, Z., Alilou Kh. (2019). The effect of population age structure on Iran's economic security. Quarterly Journal of Economic Research, 19, 125-159. Available at: https://ecor.modares.ac.ir/browse.php?a_id=15311\&sid=18\&slc_lang=en.

10. Faraji S., Hassan A., Mahmoudi Chenari, H., Bagheri M., Khodadad M. (2018). Spatial distribution analysis of population aging in Iran. Journal of Parliament and Strategy, 25(96), 296-265. Available at: https://www.sid.ir/en/journal/ViewPaper.aspx?id=649280.

11. Gietel-Basten, Stuart, Vladimir Mau, Warren Sanderson, Sergei Scherbov, and Sergey Shulgin (2020). Ageing in Russia: a regional appraisal. Journal of Population Ageing, 13(1), 63-80. Available at: https://www.researchgate.net/publication/330646581_Ageing_in_Russia_a_Regional_Appraisal.

12. Hedges, Sophie, Rebecca Sear, Jim Todd, Mark Urassa, and David W. Lawson (2018). Trade-offs in children's time allocation: mixed support for embodied capital models of the demographic transition in Tanzania. Current Anthropology, 59(5), 644-654. Available at: https://www.journals.uchicago.edu/doi/abs/10.1086/699880.

13. Heffner, Krystian, Brygida Klemens, and Brygida Solga (2019). Challenges of Regional Development in the Context of Population Ageing. Analysis Based on the Example of Opolskie Voivodeship. Sustainability, 11(19), 5207, DOI: https://doi.org/10.3390/su11195207.

14. Ingersoll-Dayton, Berit (2011). The development of culturally-sensitive measures for research on ageing. Ageing \& Society, 31(3), 355-370. https://www.cambridge.org/core/journals/ageing-and-society/article/abs/developmentof-culturallysensitive-measures-for-research-on-ageing/E34124D58DD37058760773D985A8C811.

15. Knodel, John, and Bussarawan Teerawichitchainan (2017). Aging in Myanmar. The Gerontologist, 57(4), 599-605. Available at: https://doi.org/10.1093/geront/gnw211. 
16. Korotayev, Andrey, Jack A. Goldstone, and Julia Zinkina (2015). Phases of global demographic transition correlate with phases of the Great Divergence and Great Convergence. Technological Forecasting and Social Change, 95, 163-169. Available at: https://repository.ust.hk/ir/Record/1783.1-75102.

17. Kurek, Sławomir (2011). Population changes in Poland: a second demographic transition view. ProcediaSocial and Behavioral Sciences, 19, 389-396. Available at: https://doi.org/10.1016/j.sbspro.2011.05.146.

18. Li, Junming, Xiulan Han, Xiangxue Zhang, and Sixian Wang (2019). Spatiotemporal evolution of global population ageing from 1960 to 2017. BMC Public Health, 19(1), 127. DOI: https://doi.org/10.1186/s12889019-6465-2.

19. Lutz, Wolfgang, Warren Sanderson, and Sergei Scherbov (2008). The coming acceleration of global population ageing. Nature, 451(7179), 716-719. DOI: 10.1038/nature06516.

20. Macia, Enguerran, Dominique Chevé, and Joann M. Montepare (2019). Demographic aging and biopower. Journal of Aging Studies, 51, 100820. Available at: https://read.qxmd.com/read/31761093/demographicaging-and-biopower.

21. Malhotra, Rahul, Mary Ann C. Bautista, Andre Matthias Müller, Su Aw, Gerald Choon Huat Koh, Yin-Leng Theng, Stephen James Hoskins et al. (2019). The aging of a young nation: population aging in Singapore. The Gerontologist, 59(3), 401-410. Available at: https://ink.library.smu.edu.sg/cgi/viewcontent.cgi?article=3265\&context=soe_research.

22. Mamun, Shamsul Arifeen Khan, Mohammad Mafizur Rahman, and Rasheda Khanam (2020). The relation between an ageing population and economic growth in Bangladesh: Evidence from an endogenous growth model. Economic Analysis and Policy, 66, 14-25. Available at: https://doi.org/10.1016/j.eap.2020.02.001.

23. O'Brien, Elizabeth (2016). Planning for population ageing: implications of local demographic, spatial and fiscal differences. International Planning Studies, 21(4), 317-328. Available at: https://doi.org/10.1080/13563475.2015.1125775.

24. Ofori-Asenso, Richard, Ella Zomer, Andrea J. Curtis, Sophia Zoungas, and Manoj Gambhir (2018). Measures of Population Ageing in Australia from 1950 to 2050. Journal of Population Ageing, 11(4), 367-385. Available at: $\quad$ https://link.springer.com/article/10.1007/s12062-017-92035?wt_mc=alerts.TOCjournals\&utm_source=toc\&utm_medium=email\&utm_campaign=toc_12062_11_4.

25. Partida, Virgilio (2006). Demographic transition, demographic bonus, and ageing in Mexico. In Proceedings of the United Nations Expert Group Meeting on Social and Economic Implications of Changing Population Age Structures. Ciudad de Mexico: CONAPO, pp. 285-387. Available at: https://www.un.org/en/development/desa/population/events/pdf/expert/9/full_report.pdf.

26. Reher, David Sven, Glenn Sandström, Alberto Sanz-Gimeno, and Frans WA van Poppel (2017). Agency in fertility decisions in Western Europe during the demographic transition: A comparative perspective. Demography, 54(1), 3-22. DOI: 10.1007/s13524-016-0536-0.

27. Sabzalian, Amir, Majid Kaffashi, and Bahman Bayangani (2019). Rural Ageing: Iran is on the Brink of a New Social Problem. International Journal of Social Sciences (IJSS), 9(3), 9-18. Available at: http://ijss.srbiau.ac.ir/article 14868 7a55f9d7b47185e4e664bacccb65f4b5.pdf.

28. Salvati, Luca, Margherita Carlucci, Pere Serra, and Ilaria Zambon (2019). Demographic Transitions and Socioeconomic Development in Italy, 1862-2009: A Brief Overview. Sustainability, 11(1), 242. Available at: https://doi.org/10.3390/su11010242.

29. Shiri M., Rostami E. (2018). Economic, social and demographic characteristics of the elderly based on the results of the general population and housing census of 2016. Statistics Research Institute, Statistics Center of Iran. Available at: https://www.amar.org.ir/english/Population-and-Housing-Censuses.

30. Shryock, H. S., and J. S. Siegel (1971). The methods and materials of demography: the life table. Washington DC, US Bureau of the Census, 443-446. Available at: http://www.ru.ac.bd/wpcontent/uploads/sites/25/2019/03/402_9_Shryock_Methods-and-Meterials.pdf.

31. Thompson W.S. (1929). Population. American Journal of Sociology, 34(6), 959-975. Available at: https://doi.org/10.1086/214874.

32. United Nations, 2019. Department of Economic and Social Affairs, Population Division, World Population Aging 2019: Highlights (ST/ESA/SER.A/430). Available at: 
https://www.un.org/en/development/desa/population/publications/pdf/ageing/WorldPopulationAgeing2019Highlights.pdf.

33. Véron, Jacques (2019). First to the Second Demographic Transition. DOI:10.1016/b978-0-12-8012383.11334-0.

34. Yuan, Xin, and Yuan Gao (2020). Demographic transition and economic miracles in China: an analysis based on demographic perspective. International Journal of Economic Policy Studies, 14(1), 25-45. Available at: https://ideas.repec.org/a/spr/ijoeps/v14y2020i1d10.1007_s42495-019-00030-0.html.

35. Zaidi B., Morgan S.P. (2017). The second demographic transition theory: A review and appraisal. Annual Review of Sociology, 43, pp. 473-492. DOI: 10.1146/annurev-soc-060116-053442.

36. The United Nations, 2020. Available at: https://www.un.org/en/sections/issuesdepth/ageing/\#: : :text=Trends\%20in\%20Population\%20Ageing\&text=According\%20to\%20data\%20from\% 20World,be\%20aged\%2065\%20or\%20over. 